Research Article

\title{
Microbiological Profile and Antibiotic Sensitivity Pattern of Bacteria in Diabetic Foot Ulcers in a Tertiary Care Hospital
}

\author{
Prabhat Gautam Roy', Kuldeep Kumar ${ }^{2}$, NP Singh ${ }^{3}$, Gajender Singh Ranga ${ }^{4}, \underline{\text { S Giri }}^{5}$
}

${ }^{1}$ Senior Resident, ${ }^{2}$ Assistant Professor, ${ }^{4,5}$ Director Professor, Department of Medicine, University College of Medical Sciences and Guru Teg Bahadur Hospital, Delhi, India.

${ }^{3}$ Director Professor \& Head, Department of Microbiology, University College of Medical Sciences and Guru Teg Bahadur Hospital, Hospital, Delhi, India.

DOI: https://doi.org/10.24321/2349.7181.202101

I $\quad \mathbf{N} \quad \mathbf{F}$

\section{Corresponding Author:}

Gajender Singh Ranga, University College of Medical Sciences and Guru Teg Bahadur Hospital,

Delhi, India.

E-mail Id:

gajenderranga@rediffmail.com

Orcid Id:

https://orcid.org/0000-0002-4535-6575

How to cite this article:

Roy PG, Kumar K, Singh NP, Ranga GS, Giri S. Microbiological Profile and Antibiotic Sensitivity Pattern of Bacteria in Diabetic Foot Ulcers in a Tertiary Care Hospital. J Adv Res Med. 2021;8(1):1-8.

Date of Submission: 2021-01-29

Date of Acceptance: 2021-03-30
$\begin{array}{llllllll}\mathbf{A} & \mathbf{B} & \mathbf{S} & \mathbf{T} & \mathbf{R} & \mathbf{A} & \mathbf{C} & \mathbf{T}\end{array}$

Introduction: Diabetic foot is any foot pathology due to diabetes or sequelae of diabetes mellitus. This study was conducted to identify the common microorganisms isolated from diabetic foot and to analyse the antibiotic susceptibility pattern of bacteria isolated from diabetic foot.

Materials and Method: The study was a hospital based cross-sectional study where 146 foot ulcer samples (who had type 2 diabetes) were analysed. Swabs were collected from the edge and margins of ulcers, and organisms were identified by gram staining culture and biochemical reactions.

Result: Out of 146 patients, 69 specimens showed growth of organisms. Total 84 aerobic organisms were isolated and out of them, 64 cases showed bacterial growth, in which 84 bacteria were isolated, which represented an average of 1.28 organisms per case. Among these organisms, 62 gram-negative and 22 gram-positive organisms were isolated. E. coli was the most common gram-negative isolate (23.81\%), followed by Pseudomonas aeruginosa (21.4\%), and Klebsiella pneumonia $(8.33 \%)$, while among gram-positive bacteria, $S$. aureus was the most common isolate $(22.6 \%)$.

Conclusion: Incidence of growth was $47.2 \%$ in which E. coli $(23.8 \%)$ was the most common isolate. Gram-negative bacteria were more common than gram-positive bacteria. Diabetic foot infections are polymicrobial in nature.

Keywords: Diabetic Foot, Gram-Negative, E. coli, S. aureus

\section{Introduction}

Diabetes mellitus is a rapidly expanding modern epidemic that currently affects 422 million people worldwide. ${ }^{1}$ In 2000 ,
Wild et al. predicted the global burden of diabetes to double globally from 171 million (in 2000) to 366 million (in 2030) with a maximum rise expected in India. ${ }^{2}$ Besides mortality, diabetes mellitus also carries significant morbidity with it 
in the form of cardiovascular complications, neuropathy, nephropathy, recurrent infections, obstetric complications, and foot ulcers. ${ }^{2}$

Diabetic foot is any foot pathology due to diabetes or sequelae of diabetes mellitus. Diabetic foot syndrome encompasses infections, ulcers and neuropathic osteoarthropathy. Global diabetic foot ulcer prevalence is $6.3 \%$.It is higher in type 2 diabetes mellitus (6.4\%) as compared to type 1 diabetes mellitus (5.5\%). ${ }^{3}$ The importance of diabetic foot ulcer can be understood from the fact that nearly a quarter $(24.4 \%)$ of total health expenditure amongst the diabetic population was related to foot complication. ${ }^{4}$ Diabetic foot accounts for significant morbidity in the form of skin changes, loss of sensation in feet, intermittent claudication, and development of calluses in feet followed by ulcer formation which may get infected and culminate in the need for amputation as the only viable measure of treatment. Diabetic patients with leg and foot ulcers also have a lower 5 year survival (43\%) as compared to non-diabetic ulcerated subjects (56\%) and general population controls (68\%). ${ }^{5}$

Like any other infection, eventual treatment lies in administering the antibiotic based on an isolated organism and culture sensitivity. As sensitivity pattern is available only the 48-72 hours of inoculation and is highly variable amongst various institutes and even amongst patients admitted under ICU and general wards of the same hospital, the need for administering a common and effective antibiotic at the earliest is of paramount importance to accelerate healing and reducing morbidity. The present study was undertaken to identify the common microorganisms isolated from diabetic foot, analyse the antibiotic susceptibility pattern of bacteria, and suggest an effective empirical antibiotic therapy for diabetic foot infected with various bacteria in the medical wards of our hospital.

\section{Materials and Methods}

\section{Study Design, Settings and Participants}

It was a hospital based cross-sectional study conducted over a period of 18 months from November 2017 to April 2019 in the Department of Medicine and Microbiology of a tertiary care teaching hospital in New Delhi, India. 146 newly diagnosed or known diabetic patients aged 40 years and more and having diabetic foot ulcer (Wagner-Meggitt grade 2 or higher) were selected for the study. Patients with amputated feet or with other ulcers like traumatic ulcer, scar ulcer, venous ulcers, and malignant ulcers were excluded from the study.

Wagner- Meggitt Grading for Diabetic Foot Ulcers.

- Grade 0: Intact skin

- Grade 1: Superficial ulcer

- Grade 2: Deep ulcer extending to bone, tendon, or joint

- Grade 3: Deep ulcer with abscess or osteomyelitis
- Grade 4: Forefoot gangrene

- Grade 5: Whole foot gangrene

\section{Data Collection}

After taking written informed consent, patients were subjected to detailed history and physical examination with special emphasis on risk factors for diabetic foot. Haematological investigations like CBC, KFT, and lipid profile were done for all the subjects. Apart from haematological investigations, an x-ray of the affected limb including the site of ulcer, and a pus swab and/ or tissue biopsy were also done.

These patients' diabetic foot ulcers were washed with normal saline/ distilled water and necrotic materials (if any) were debrided. After that, a tissue biopsy/ pus swab was taken from the junction of healthy and unhealthy tissue. This sample was collected at the time of admission before starting antibiotic therapy. Pus swab was immediately sent to microbiology lab where gram staining was performed on the sample. After gram staining, the organisms were identified as per standard techniques mentioned in Mackie McCartney literature. ${ }^{6}$

Tissue specimens obtained by biopsy were transported to the microbiology lab in normal saline. The samples obtained from diabetic foot ulcer were inoculated on Blood agar and MacConkey agar. These samples were incubated at $37^{\circ} \mathrm{C}$ for 16-18 hours after which the growth obtained on culture plates were subjected to antibiotic sensitivity testing.

Antibiotic sensitivity testing was done by the Kirby Bauer disc diffusion method as per CLSI guidelines. ${ }^{7}$ The following antibiotics were used for culture sensitivity testing:

- Amikacin

- Gentamicin

- Linezolid

- Piperacillin-tazobactam

- Meropenem

- Ciprofloxacin

- Teicoplanin

- Vancomycin

- Ceftazidime

- Amoxicillin-Clavulanate

- Clindamycin

- Polymyxin B/ Colistin

- $\quad$ Tigecycline

An attempt was made for isolation and identification of anaerobic microbes. Samples for anaerobic culture (pus/ swab/ tissue) were collected and immediately transported to the microbiology lab in thioglycolate broth. The samples were kept in an incubator for enrichment for 24 hours. After enrichment, they were inoculated on Brain Heart Infusion (BHI) agar and Blood agar, and were kept for anaerobic culture. Pseudomonas was used as control 
in anaerobic culture. Anaerobic media was created in a standard anaerobic jar using a gas-pack. The culture was read after 48 hours. The patients included in this study were treated empirically as per standard guidelines. Once culture sensitivity reports were available, the antibiotics were changed according to the antibiogram.

\section{Statistical Analysis}

Data were analysed and statistically evaluated using SPSS software, version 17 (Chicago II, USA). Quantitative data were expressed in mean and standard deviation, while qualitative data were expressed in percentage. Statistical differences between the proportions were tested by chisquare test or Fisher's exact test. ' $p$ ' value less than 0.05 was considered statistically significant.

\section{Ethical Issues}

The study was approved by the Institutional Ethical Committee. All the participants were explained the purpose of the study. Confidentiality was assured to them and informed written consent was obtained.

\section{Result}

The study population comprised 107 males and 39 females. The mean age of study subjects was $54.61 \pm 9.98$ years while the mean BMI was $22.75 \pm 2.99 \mathrm{~kg} / \mathrm{m}^{2} .115(78.8 \%)$ patients were taking $\mathrm{OHA}$ as treatment whereas 14 (9.6\%) were on insulin. 17 (11.6\%) patients were taking no treatment for diabetes. The mean duration of diabetes was $166.11 \pm 94.05$ months. $43 \%$ of the subjects were smokers and $27 \%$ were tobacco chewers. $58.9 \%$ of the patients had concomitant hypertension and $52.1 \%$ of the patients had involvement of right foot. 70 (47.9\%) patients had active discharge at the time of presentation and $48.6 \%$ had neurological involvement.

Out of 146 patients, 69 (47.2\%) patients showed microbiological growth, and out of them, 64 cases showed bacterial growth in which 84 bacteria were isolated, which represents an average of 1.28 organisms per case.

Majority of the infections were caused by gram-negative bacteria which constituted $73.81 \%$ of the infections, and gram-positive bacteria accounted for $26.19 \%$ (Table 1 ). Among gram-negative bacteria, E. coli was the most common isolate accounting for $23.81 \%$ of the infections, followed by Pseudomonas aeruginosa, Klebsiella pneumoniae, and Proteus mirabilis constituting $21.4 \%, 8.33 \%$, and $7.14 \%$ respectively, while among gram-positive bacteria, S. aureus was the most common isolate (22.6\%).

Table 2, shows the result of the test for susceptibility to the commonly used antibiotics. Methicillin-Resistant S. Aureus
(MRSA) showed $100 \%$ sensitivity to vancomycin, teicoplanin, and linezolid. The sensitivity towards tetracycline, clindamycin, clotrimazole, gentamicin, and erythromycin were $75 \%, 50 \%, 40 \%, 20 \%$, and $11.1 \%$ respectively. $E$. coli showed $100 \%$ sensitivity to colistin, polymyxin B and netilmicin. The sensitivity of $E$. coli towards amikacin, gentamicin, and meropenem, were $66.67 \%, 64.7 \%$, and $63.6 \%$ respectively. The sensitivity towards tobramycin, chloramphenicol, and tigecycline was $50 \%$. The sensitivity of $E$. coli to piperacillin-tazobactam, imipenem, and ciprofloxacin were $35.7 \%, 33.3 \%$, and $14.3 \%$ respectively.

Table I.Microorganisms Isolated from Diabetic Foot Ulcers

\begin{tabular}{|c|c|c|}
\hline \multicolumn{3}{|c|}{ Total Microbes Isolated ( $n=91)$} \\
\hline Bacteria $(n=84)$ & $\begin{array}{l}\text { Number } \\
\text { (n) }\end{array}$ & $\begin{array}{c}\text { Percentage } \\
(\%)\end{array}$ \\
\hline $\begin{array}{c}\text { Gram-positive } \\
\text { Bacteria }\end{array}$ & 22 & 26.19 \\
\hline $\begin{array}{c}\text { Methicillin-resistant } S . \\
\text { aureus }\end{array}$ & 10 & 11.9 \\
\hline $\begin{array}{c}\text { Methicillin-sensitive } S . \\
\text { aureus }\end{array}$ & 9 & 10.71 \\
\hline $\begin{array}{l}\text { Beta-haemolytic } \\
\text { Streptococcus }\end{array}$ & 1 & 1.19 \\
\hline Enterococcus & 2 & 2.38 \\
\hline $\begin{array}{c}\text { Gram-negative } \\
\text { Bacteria }\end{array}$ & 62 & 73.81 \\
\hline E. Coli & 20 & 23.8 \\
\hline P. Aeruginosa & 18 & 21.4 \\
\hline K. (pneumoniae) & 7 & 8.33 \\
\hline K. Oxytoca & 2 & 2.38 \\
\hline P. Mirabilis & 6 & 7.14 \\
\hline P. vulgaris & 2 & 2.38 \\
\hline A. baumannii & 5 & 5.95 \\
\hline Citrobacter & 2 & 2.38 \\
\hline \multicolumn{3}{|l|}{ Fungi ( $n=7)$} \\
\hline Candida albicans & 3 & 3.2 \\
\hline Non-albicans Candida & 4 & 4.3 \\
\hline Anaerobes $(n=0)$ & 0 & 0 \\
\hline
\end{tabular}


Table 2.Data regarding Sensitivity of Microorganisms to Various Antibiotics

\begin{tabular}{|c|c|c|c|c|c|c|c|c|c|c|c|c|}
\hline & $\begin{array}{l}\text { Methicillin- } \\
\text { Resistant } \\
\text { Staph } \\
\text { aureus } \\
(n=10)\end{array}$ & $\begin{array}{c}\text { Staphy- } \\
\text { lococcus } \\
\text { aureus } \\
(n=9)\end{array}$ & $\begin{array}{l}\text { Pseudo- } \\
\text { monas } \\
\text { aeruginosa } \\
(n=8)\end{array}$ & $\begin{array}{c}\text { Acinet- } \\
\text { obacter } \\
\text { baumannii } \\
(n=5)\end{array}$ & $\begin{array}{c}\text { Entero- } \\
\text { coccus } \\
(n=2)\end{array}$ & $\begin{array}{c}\text { Esche- } \\
\text { richia } \\
\text { coli } \\
(n=20)\end{array}$ & $\begin{array}{c}\text { Proteus } \\
\text { mirabilis } \\
(n=6)\end{array}$ & $\begin{array}{c}\text { Proteus } \\
\text { vulgaris } \\
(n=2)\end{array}$ & $\begin{array}{c}\text { Klebsiella } \\
\text { pneum- } \\
\text { oniae } \\
(n=7)\end{array}$ & $\begin{array}{l}\text { Klebs- } \\
\text { iella } \\
\text { oxytoca } \\
(n=2)\end{array}$ & $\begin{array}{c}\text { Citro- } \\
\text { bacter } \\
(n=2)\end{array}$ & $\begin{array}{c}\text { Beta- } \\
\text { haemolytic } \\
\text { Streptococci } \\
\quad(n=1)\end{array}$ \\
\hline Clotrimazole & $4(40 \%)$ & $\begin{array}{c}5 \\
(83.3 \%)\end{array}$ & 0 & 0 & - & 0 & 0 & - & $2(40 \%)$ & $1(100 \%)$ & 0 & - \\
\hline Vancomycin & 7 (100\%) & $6(100 \%)$ & - & - & $\begin{array}{c}2 \\
(100 \%)\end{array}$ & - & - & - & - & - & - & - \\
\hline Teicoplanin & 2 (100\%) & $1(50 \%)$ & - & 0 & 0 & 0 & - & - & - & - & - & - \\
\hline Gentamicin & $1(20 \%)$ & $3(100 \%)$ & 7 (38.9\%) & 0 & 0 & $\begin{array}{c}11 \\
(64.7 \%)\end{array}$ & 0 & $1(50 \%)$ & $6(75 \%)$ & $2(100 \%)$ & 0 & - \\
\hline Amikacin & - & $1(100 \%)$ & $6(46.1 \%)$ & 0 & - & $\begin{array}{c}10 \\
(66.7 \%)\end{array}$ & $1(25 \%)$ & $\begin{array}{c}2 \\
(100 \%)\end{array}$ & 7 (100\%) & 2 (100\%) & $1(50 \%)$ & - \\
\hline Netilmicin & - & - & $2(33.3 \%)$ & $1(100 \%)$ & - & $3(100 \%)$ & 0 & - & $1(50 \%)$ & - & $1(50 \%)$ & - \\
\hline Tetracycline & $3(75 \%)$ & $3(100 \%)$ & - & - & 0 & - & - & - & - & - & - & - \\
\hline Tigecycline & - & - & - & - & - & $1(50 \%)$ & - & - & $1(100 \%)$ & - & - & - \\
\hline Erythromycin & $1(11.1 \%)$ & $\begin{array}{c}4 \\
(66.7 \%)\end{array}$ & - & - & - & - & - & - & - & - & - & 0 \\
\hline Clindamycin & $5(50 \%)$ & $4(80 \%)$ & - & $1(100 \%)$ & - & - & - & - & - & - & - & 0 \\
\hline Cefotaxime & 0 & - & 0 & 0 & - & 0 & 0 & $1(50 \%)$ & $2(33.3 \%)$ & $1(100 \%)$ & 0 & 0 \\
\hline Ciprofloxacin & 0 & $1(50 \%)$ & $3(37.5 \%)$ & 0 & - & $\begin{array}{c}1 \\
(14.3 \%)\end{array}$ & 0 & - & $2(66.7 \%)$ & $1(100 \%)$ & - & - \\
\hline
\end{tabular}

ISSN: 2349-7181

DOI: https://doi.org/10.24321/2349.7181.202101 


\begin{tabular}{|c|c|c|c|c|c|c|c|c|c|c|c|c|}
\hline Cefoxitin & 0 & $6(100 \%)$ & - & - & - & - & - & - & - & - & - & - \\
\hline Meropenem & - & - & $9(75 \%)$ & 0 & - & $\begin{array}{c}7 \\
(63.6 \%)\end{array}$ & 2 (66.7\%) & $\begin{array}{c}1 \\
(100 \%)\end{array}$ & $6(100 \%)$ & $2(100 \%)$ & $1(100 \%)$ & - \\
\hline Imipenem & - & - & $1(50 \%)$ & 0 & - & $\begin{array}{c}1 \\
(33.3 \%)\end{array}$ & - & - & - & - & - & - \\
\hline Ertapenem & - & - & - & - & - & - & - & - & - & - & 0 & - \\
\hline $\begin{array}{l}\text { Piperacillin- } \\
\text { Tazobactam }\end{array}$ & 0 & - & 7 (58.3\%) & $1(33.3 \%)$ & - & $\begin{array}{c}5 \\
(35.7 \%)\end{array}$ & $2(50 \%)$ & $1(50 \%)$ & $6(85.7 \%)$ & $2(100 \%)$ & $1(100 \%)$ & - \\
\hline Aztreonam & - & - & $8(57.1 \%)$ & 0 & - & $\begin{array}{c}1 \\
(6.25 \%)\end{array}$ & 2 (66.7\%) & $1(50 \%)$ & $2(33.3 \%)$ & $1(50 \%)$ & $1(33.3 \%)$ & - \\
\hline Tobramycin & - & - & 7 (50\%) & 0 & - & $2(50 \%)$ & - & - & - & - & - & - \\
\hline $\begin{array}{l}\text { Ampicillin- } \\
\text { Sulbactam }\end{array}$ & - & $1(100 \%)$ & - & 0 & - & - & - & - & - & - & - & - \\
\hline Colistin & - & - & 3 (100\%) & $1(100 \%)$ & - & $1(100 \%)$ & - & - & - & - & - & - \\
\hline Polymyxin-B & - & - & $5(100 \%)$ & $2(100 \%)$ & - & $8(100 \%)$ & - & - & 2 (100\%) & - & $2(100 \%)$ & - \\
\hline Ampicillin & 0 & - & - & - & $\begin{array}{c}2 \\
(100 \%)\end{array}$ & 0 & - & - & - & - & - & - \\
\hline Linezolid & $6(100 \%)$ & $4(40 \%)$ & - & - & $\begin{array}{c}2 \\
(100 \%)\end{array}$ & - & - & - & - & - & - & - \\
\hline Ceftazidime & - & - & $8(50 \%)$ & - & - & 0 & $1(33.3 \%)$ & - & $2(40 \%)$ & - & - & - \\
\hline Chloramphenicol & - & - & - & 0 & $1(50 \%)$ & $1(50 \%)$ & 0 & - & - & - & 0 & - \\
\hline Carbapenem & - & - & 0 & - & - & - & - & - & - & - & - & - \\
\hline Levofloxacin & 0 & - & - & - & - & - & 0 & - & - & - & - & - \\
\hline
\end{tabular}




\section{Discussion}

Diabetic foot ulcer is a common complication requiring hospitalization among diabetic patients. It is the most common cause of non-traumatic lower-extremity amputations. ${ }^{8}$ In this study, we tried to evaluate the degree of this problem in our institution.

In our study, males outnumbered females by a ratio of 2.74:1. A similar ratio of males outnumbering females was also reported by Sekhar $\mathrm{M}$ et al. ${ }^{9}$ with a male:female ratio of 2.5:1. Al Benwan et al. reported a ratio of 2.8:1 in a study from Kuwait. ${ }^{10}$ Similarly, Jain et al. have reported a ratio of 2.1:1 in a study conducted in Gujarat. ${ }^{8}$ The average age of patients enrolled in our study was $54.61 \pm 9.98$ years. As both macrovascular and microvascular complications such as neuropathy and vasculopathy in diabetes develop after several years of onset of type 2 DM, it was not surprising that our patients were in the middle age group.

Our study yielded bacterial growth in $47.25 \%$ of the samples, and $43.83 \%$ of the samples yielded a positive aerobic culture. This value was lower than that of various similar studies (90\%). ${ }^{11}$ A possible explanation for the same could be that they employed molecular PCR techniques for the isolation of bacteria which is more sensitive than the conventional culture techniques we used. Eurodiale study was a large multicentric study that used conventional culture based techniques to isolate bacteria from diabetic foot. ${ }^{12}$ They reported a culture positivity of $58 \%$. An explanation for the low yield on culture could be that our hospital is a tertiary care setup where most patients were referred cases and most of them received some amount of primary care before visiting our hospital. Since they were already exposed to antibiotics before visiting our hospital, a negative culture report was not very surprising.

In the present study, 84 bacteria were isolated from 64 cases which represented an average of 1.28 organisms per case, and majority of the organisms were gram-negative (73.8\%). This was in accordance with most of the studies carried out worldwide that had also reported a greater prevalence of gram-negative organisms infecting diabetic foot ulcers. ${ }^{13}$ Among gram-negative organisms, the most common organisms we isolated were $E$. coli $(23.8 \%)$ and $P$. aeruginosa $(21.4 \%)$ which was similar to the observations made by Murli TS et al. ${ }^{14}$ Similar reports were also published by Bansal et al. ${ }^{13}$ and Ramakant et al. ${ }^{15}$

A higher prevalence of gram-negative organisms in diabetic foot ulcer is a well-known fact. Ulcers which are deep, chronically infected, or previously treated with antibiotics are more likely to be co-infected with Enterococci, Enterobacteriaceae, Pseudomonas aeruginosa, and anaerobes. Microbes infecting diabetic foot also vary with changing geographical location and climate that is exemplified by gram-negative organisms being the predominant culture isolate in tropical areas like Africa and Asia. ${ }^{16}$

Amongst the gram-positive organisms, S. aureus (22.61\%) was the most common organism isolated, followed by Enterococcus (2.38\%) and Beta haemolytic streptococci $1.19 \%$. This finding was also in agreement with multiple studies conducted across India. Bansal E et al. also reported that S. aureus (19\%) was the most common gram-positive organism isolated in their study. ${ }^{13}$ Murali TS et al. also isolated microbes from diabetic foot and they too found that S. aureus was the most common gram-positive organism. ${ }^{14}$ In a similar study conducted by Chavan SK et al., it was found that $S$. aureus was the commonest gram-positive organism isolated. ${ }^{17}$

In our study, MSSA strains were susceptible to piperacillintazobactam, meropenem, amoxicillin-clavulanate, clindamycin, and levofloxacin. ${ }^{18}$ Endimiani et al.conducted a study to describe the emergence of linezolid-resistant $S$. aureus and to look into the reasons for increasing resistance. ${ }^{19}$ MRSA has been considered as the pathogen of concern in diabetic foot ulcer for a very long time. Recently, the emergence of community-acquired MRSA has been recorded. ${ }^{18}$ In our study, MRSA contributed to $11.9 \%$ of total isolates. Another study from France in 2004 has reported a much higher isolation rate (18\%) of MRSA. ${ }^{20}$

Enterococcus showed $100 \%$ sensitivity to vancomycin, ampicillin and linezolid. Sensitivity to chloramphenicol was $50 \%$. All the Enterococci isolated in our study were resistant to gentamicin. Similar results showing $100 \%$ sensitivity to vancomycin and linezolid along with lower sensitivity to gentamicin have also been reported by Shettigar K et al. ${ }^{21}$

E. coli has emerged as the major (23.8\%) gram-negative pathogen in our study followed by Pseudomonas aeruginosa (21.4\%). Pseudomonas aeruginosa is one of the prevalent organisms in diabetic foot infections. In various studies conducted across northern India, it has emerged as the most prevalent microorganism isolated from diabetic foot infections. ${ }^{13,15}$ However, there have been studies like the one by Tiwari $S$ et al.which reported $E$. coli as the most common gram-negative organism. ${ }^{22} \mathrm{~A}$ study with a larger sample size is desirable to get a better estimate of the most common gram-negative organism infecting diabetic foot.

All the strains of $E$. coli isolated from our study were sensitive to colistin, polymyxin B and netilmicin. Sensitivity to piperacillin-tazobactam was $35.7 \%$. This was in contrast with the findings of Shailesh $\mathrm{K}$ Shahi et al. ${ }^{23}$ who analysed antibiotic sensitivity of $E$. coli isolated from diabetic foot and reported $100 \%$ sensitivity to piperacillin-tazobactam. This may be explained by the development of resistance. Possible reasons for the resistance of $E$. coli to piperacillin- 
tazobactam could be the presence of AmpC producers, possible TEM-1 hyperproducers, and multiple $\beta$-lactamases in individual organisms of a given isolate. ${ }^{24}$

We also attempted culturing anaerobic microorganisms. ${ }^{26}$ samples from diabetic foot were also simultaneously tested for anaerobic growth. However, none of the samples yielded positive growth. Literature has revealed that anaerobes are implicated in a minority $(<15 \%)$ of diabetic foot ulcer infections. ${ }^{10}$

Fungal infection was observed in $4.8 \%$ of the patients. In this study, we isolated three $C$. albicans and four non-albicans Candida from diabetic foot ulcers. A similar study conducted in southern Iran by M. Anvarinejad et al. reported a 6\% fungal prevalence in diabetic foot ulcers. ${ }^{25}$ Some studies noted a higher prevalence of Candida spp, whereas others reported opportunistic mould species as the causative agents of fungal infections in diabetic foot. ${ }^{26,27}$

An alarming observation was the resistance of multiple bacteria to piperacillin-tazobactam. The sensitivity of various bacteria was $58.3 \%$ for Pseudomonas, $33.3 \%$ for Acinetobacter, $35.7 \%$ for E. coli, and $50 \%$ for Proteus. The following mechanisms had been proposed for resistance to piperacillin-tazobactam: (i) presence of AmpC producers, (ii) TEM-1 hyperproducers, and (iii) multiple $\beta$-lactamases in individual organisms of a given isolate. ${ }^{24}$

In light of the globally increasing prevalence of drugresistant organisms, the need for rational use of antibiotics is essential..$^{20}$ In order to minimize the emergence of antibiotic resistance during therapy, it is important to try and avoid antibiotics that encourage transfer of resistance genes, to avoid selection of resistant variants from susceptible pathogens and to avoid ablation of antibiotic susceptible normal flora. Careful antimicrobial sensitivity testing and formulation of guidelines that decide empirical antibiotic treatment in diabetic foot are highly desirable. In view of the findings in our study, we suggest using vancomycin for gram-positive isolates and meropenem + colistin/ polymyxin $\mathrm{B}$ for gram-negative isolates. The choice of antibiotics can later be modified as per culture and sensitivity reports.

\section{Limitation}

Anaerobic flora of diabetic foot could not be characterized as all the samples could not be put for anaerobic cultures due to limited availability of resources. We employed conventional culture methods to isolate microbes from samples. A study with newer techniques like 16s RNA sequencing is desirable for a better yield and characterization of microorganisms. Lastly, fungi isolated from cultures were not put for antimicrobial sensitivity testing owing to lack of resources.

\section{Funding Statement}

We would like to acknowledge the Intramural Research Grant (IMRG), University College of Medical Sciences (UCMS) for extending their support in the form of a financial grant which was indispensable for carrying out this research work.

\section{Acknowledgement}

We are thankful to all the participants of the study.

\section{Conflict of Interest: None}

\section{References}

1. WHO [Internet]. Global report on diabetes. 2017 [cited 2019 Feb 17]. Available from: https://www.who.int/ diabetes/global-report/en/

2. Wild S, Roglic G, Green A, Sicree R, King H. Global prevalence of diabetes: estimates for the year 2000 and projections for 2030. Diabetes Care. 2004;27(5): 1047-1053. [PubMed] [Google Scholar].

3. Zhang P, Lu J, Jing Y, Tang S, Zhu D, Bi Y. Global epidemiology of diabetic foot ulceration: a systematic review and meta-analysis. Ann Med. 2017 Mar;49(2):106-16. [PubMed] [Google Scholar].

4. Sargen MR, Hoffstad O, Margolis DJ. Geographic variation in Medicare spending and mortality for diabetic patients with foot ulcers and amputations. J Diabetes Complications. 2013 Mar-Apr;27(2):128. [PubMed] [Google Scholar].

5. Morbach S, Furchert H, Gröblinghoff $U$, Hoffmeier $\mathrm{H}$, Kersten K, Klauke G-T et al. Long-term prognosis of diabetic foot patients and their limbs: amputation and death over the course of a decade. Diabetes Care. 2012 Oct;35(10):2021-7. [PubMed] [Google Scholar]

6. Collee JG, Mackie TJ, McCartney JE. Mackie \& McCartney practical medical microbiology. [Internet]. 14th ed. New York: Churchill Livingstone; c1996. [cited 2019 May 11]. 978 p. Available from: https://www.worldcat.org/title/ mackie-mccartney-practical-medical-microbiology/ oclc/35714221

7. CLSI. [Internet]. Performance Standards for Antimicrobial Susceptibility Testing An informational supplement for global application developed through the Clinical and Laboratory Standards Institute consensus process. 26th ed. [cited 2019 May 11]. Available from: https://clsi. org/media/3481/m100ed30_sample.pdf

8. Jain M, Patel MH, Sood NK, Modi DJ, Vegad MM. Spectrum of Microbial Flora in Diabetic Foot Ulcer and Its Antibiotic Sensitivity Pattern in Tertiary Care Hospital in Ahmedabad, Gujarat. Natl J Med Res. 2012;2(3):3547. [Google Scholar].

9. Sekhar MS, Unnikrishnan MK, Rodrigues GS, Vyas N, Mukhopadhyay C. Antimicrobial susceptibility pattern 
of aerobes in diabetic foot ulcers in a South-Indian tertiary care hospital. Foot (Edinb). 2018 Dec;37:95100. [PubMed] [Google Scholar].

10. Benwan KA, Mulla AA, Rotimi VO. A study of the microbiology of diabetic foot infections in a teaching hospital in Kuwait. J Infect Public Health. 2012 Mar;5(1):1-8. [PubMed] [Google Scholar].

11. Noor S, Raghav A, Parwez I, Ozair M, Ahmad J. Molecular and culture based assessment of bacterial pathogens in subjects with diabetic foot ulcer. Diabetes Metab Syndr. 2018 May;12(3):417-21. [PubMed] [Google Scholar].

12. Prompers $L$, Huijberts $M$, Apelqvist J, Jude E, Piaggesi A, Bakker K, Edmonds M, et al. High prevalence of ischaemia, infection and serious comorbidity in patients with diabetic foot disease in Europe. Baseline results from the Eurodiale study. Diabetologia. 2007 Jan;50(1):18-25. [PubMed] [Google Scholar].

13. Bansal E, Garg A, Bhatia S, Attri AK, Chander J. Spectrum of microbial flora in diabetic foot ulcers. Indian J Pathol Microbiol. 2008 Apr-Jun;51(2):204-8. [PubMed] [Google Scholar]

14. Murali TS, Kavitha S, Spoorthi J, Bhat DV, Prasad ASB, Upton Z, et al. Characteristics of microbial drug resistance and its correlates in chronic diabetic foot ulcer infections. J Med Microbiol. 2014 Oct;63(Pt 10):1377-85. [PubMed] [Google Scholar].

15. Ramakant P, Verma AK, Misra R, Prasad KN, Chand G, Mishra $A$, et al. Changing microbiological profile of pathogenic bacteria in diabetic foot infections: time for a rethink on which empirical therapy to choose? Diabetologia. 2011 Jan;54(1):58-64. [PubMed] [Google Scholar].

16. Zubair M, Malik A, Ahmad J. Clinico-microbiological study and antimicrobial drug resistance profile of diabetic foot infections in North India. Foot (Edinb). 2011 Mar;21(1):6-14. [PubMed] [Google Scholar].

17. Chavan SK, Karande GS, Chavan KB. Bacterial Profile and Pattern of Antimicrobial Drug Resistance in Diabetic Foot Ulcers at Tertiary Care Hospital. Int J Med Res Rev. 2015 Jan-Feb;3(1):97-105.

18. Citron DM, Goldstein EJC, Merriam CV, Lipsky BA, Abramson MA. Bacteriology of moderate-tosevere diabetic foot infections and in vitro activity of antimicrobial agents. J Clin Microbiol. 2007 Sep;45(9):2819-28. [PubMed] [Google Scholar].

19. Endimiani A, Blackford M, Dasenbrook EC, Reed MD, Bajaksouszian S, Hujer AM, et al. Emergence of linezolidresistant Staphylococcus aureus after prolonged treatment of cystic fibrosis patients in Cleveland, Ohio. Antimicrob Agents Chemother. 2011 Apr;55(4):168492. [PubMed] [Google Scholar].

20. Hartemann-Heurtier A, Robert J, Jacqueminet $S, H a$ Van G, Golmard JL, Jarlier V, et al. Diabetic foot ulcer and multidrug-resistant organisms: risk factors and impact. Diabet Med. 2004 Jul;21(7):710-5. [PubMed] [Google Scholar].

21. Shettigar K, Bhat DV, Satyamoorthy K, Murali TS. Severity of drug resistance and co-existence of Enterococcus faecalis in diabetic foot ulcer infections. Folia Microbiol (Praha). 2018 Jan;63(1):115-22. [PubMed] [Google Scholar].

22. Tiwari S, Pratyush DD, Dwivedi A, Gupta SK, Rai M, Singh SK. Microbiological and clinical characteristics of diabetic foot infections in northern India. J Infect Dev Ctries. 2012 Apr;6(4):329-32. [PubMed] [Google Scholar].

23. Shahi SK, Singh VK, Kumar A. Detection of Escherichia coli and associated $\beta$-lactamases genes from diabetic foot ulcers by multiplex PCR and molecular modeling and docking of SHV-1, TEM-1, and OXA-1 $\beta$-lactamases with clindamycin and piperacillin-tazobactam. PLoS One. 2013 Jul;8(7):e68234. [PubMed] [Google Scholar].

24. Lee J, Oh CE, Choi EH, Lee HJ. The impact of the increased use of piperacillin/tazobactam on the selection of antibiotic resistance among invasive Escherichia coli and Klebsiella pneumoniae isolates. Int J Infect Dis. 2013 Aug;17(8):e638-43. [PubMed] [Google Scholar].

25. Anvarinejad M, Pouladfar $G$, Japoni $A$, Bolandparvaz S, Satiary Z, Abbasi P, et al. Isolation and Antibiotic Susceptibility of the Microorganisms Isolated from Diabetic Foot Infections in Nemazee Hospital, Southern Iran. J Pathog. 2015;2015:1-7. [PubMed] [Google Scholar].

26. Nair S, Peter S, Sasidharan A, Sistla S, Kodakara A, Unni K. Incidence of Mycotic Infections in Diabetic Foot Tissue. J Culture Collections. 2006;5(1):85-9. [Google Scholar].

27. Eckhard M, Lengler A, Liersch J, Bretzel RG, Mayser $P$. Fungal foot infections in patients with diabetes mellitus --results of two independent investigations. Mycoses. 2007;50 Suppl 2:14-9. [PubMed] [Google Scholar]. 